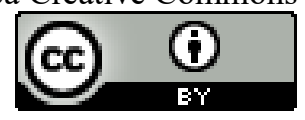

\title{
PAISAGENS FILOSÓFICAS AFRICANAS: FILOPOÉTICA DA LIBERTAÇÃO COMO DISPUTA DE IMAGINÁRIO
}

\author{
Luís Carlos Ferreira dos Santos ${ }^{1}$ \\ Eduardo David de Oliveira ${ }^{2}$
}

\begin{abstract}
Resumo: O artigo, paisagens filosóficas africanas: filopoética da libertação como disputa de imaginário, tem o objetivo de problematizar a ausência do diverso de paisagem na produção filosóficoe analisar a filopoética como disputa de imaginários, para isso, defende as filosofias africanas como espaço de ampliação do imaginário.O percurso do texto dá-se em filosofar desde a geopoética africana, no intuito de disputar os imaginários, de traçar itinerários, rotas na conexão com o todo-mundo. $\mathrm{O}$ segundo momento problematiza a importância política de habitar e ser habitado pela própria paisagem; e, por fim, a defesa da filopoética da libertação como uma ferramenta nesta disputa na guerra de imaginários. A filopoética tem a função de povoar o imaginário.
\end{abstract}

Palavras-chave: Filopoética; Filosofias Africanas; Paisagens; Imaginários.

\section{AFRICAN PHILOSOPHICAL LANDSCAPES: PHILOPOETICS OF LIBERATION AS AN IMAGINARY DISPUTE}

\begin{abstract}
The article, African philosophical landscapes: the philosophy of liberation as a dispute for the imaginary, aims to discuss the absence of the diverse landscape in philosophical production and to analyze philosophy as a dispute for the imaginary, for this purpose, defends African philosophies as a space for expanding imaginary. The course of the text takes place in philosophizing from African geopoetics, in order to dispute the imaginary, to outline itineraries, routes in connection with the whole world. The second moment questions the political importance of inhabiting and being inhabited by the landscape itself; and, finally, the defense of the philosophy of liberation as a tool in this dispute in the war of the imaginary. Philopoetics has the function of populating the imaginary.
\end{abstract}

Keywords: Philopoetic; African philosophies; Landscapes; Imaginary

\footnotetext{
${ }^{1}$ Doutor em Difusão do Conhecimento (UFBA); Mestre em Educação (UFBA); Graduado em Filosofia (UFBA); Membro do Grupo de Pesquisa Rede Africanidades. E-mail: lcarlosfsantos@gmail.com

${ }^{2}$ Professor da FACED/UFBA. Líder do Grupo de Pesquisa RedeAfricanidades, Sócio-fundador do IPADInsituto de pesquisa da afrodescendência e sócio-fundador do IFIL - Insituto de Filosofia da Libertação e atualmente coordenador da Linha de Pesquisa Conhecimento e Cultura do Doutorado Multi-institucional, Multidisciplinar em Difusão do Conhecimento.E-mail: afroduda@gmail.com
} 


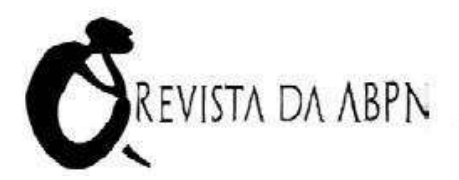

$\triangle \nabla \Delta \nabla \Delta \nabla \Delta \nabla \Delta \nabla \Delta \nabla \Delta \nabla \Delta \nabla \Delta \nabla \Delta \nabla \nabla \nabla \nabla \Delta \nabla \Delta \nabla \Delta \nabla \triangle \nabla \nabla \nabla \nabla \Delta \nabla \Delta \nabla$

PAISAJES FILOSÓFICOS AFRICANOS: LA FILOPOÉTICA DE LA LIBERACIÓN COMO UNA DISPUTA IMAGINARIA

Resumen: El artículo, Paisajes filosóficos africanos: la filosofía de la liberación como una disputa por lo imaginario, tiene como objetivo discutir la ausencia del paisaje diverso en la producción filosófica y analizar la filosofía como una disputa por lo imaginario, con este propósito, defiende las filosofías africanas como un espacio para expandirse imaginario El curso del texto tiene lugar al filosofar desde la geopoética africana, para disputar lo imaginario, para delinear itinerarios, rutas en conexión con el mundo entero. El segundo momento cuestiona la importancia política de habitar y ser habitado por el paisaje mismo; y, finalmente, la defensa de la filosofía de la liberación como herramienta en esta disputa en la guerra de lo imaginario. La filopoética tiene la función de poblar lo imaginario.

Palabra clave: Filopoético; Filosofías africanas; Paisajes; Imaginario

\section{PAYSAGES PHILOSOPHIQUES AFRICAINS: LA PHILOPOETIQUE DE LA LIBERATION COMME CONFLIT IMAGINAIRE}

Résumé: L'article, Paysages philosophiques africains: la philosophie de la libération comme dispute à l'imaginaire, vise à discuter de l'absence de paysage diversifié dans la production philosophique et à analyser la philosophie comme une dispute à l'imaginaire, à cet effet, défend les philosophies africaines comme un espace d'expansion imaginaire. Le cours du texte se déroule en philosophisant à partir de la géopoétique africaine, afin de contester l'imaginaire, de tracer des itinéraires, des itinéraires en relation avec le monde entier. Le deuxième moment interroge l'importance politique de vivre et d'être habité par le paysage lui-même; et, enfin, la défense de la philosophie de la libération comme outil de cette dispute dans la guerre de l'imaginaire. La philopoétique a pour fonction de peupler l'imaginaire.

Mot clé: Philopoétique; Philosophies africaines; Paysages; Imaginaire

\section{INTRODUÇÃO}

"O inconsciente coletivo é cultural, ou seja, adquirido" (FANON, 2008, p. 160).

O artigo, intitulado "Paisagens filosóficas africanas: filopoética da libertação como disputa de imaginários", busca compreender a paisagem como um conceito articulador do debate em torno da filopoética como filosofia negro-africana na ampliação dos imaginários. O texto, no primeiro momento, problematiza a ausência do diverso na produção filosófica em território brasileiro, evidenciando uma chave de leitura acerca da filosofia no Brasil que flerta com o absurdo do epistemicídio e com o semiocídio cultural: negação dos saberes e conhecimentos africanos e latino-americanos. Para isso, cartografa uma paisagem da filosofia no Brasil. O referencial epistemológico e simbólico europeu e

Revista da ABPN • v. 12, n. $31 \cdot \operatorname{dez} 2019$ - fev 2020, p. 113-132 
mais recentemente estadunidense busca se impor no imaginário brasileiro. É possível perceber a colonialidade do ser, a colonialidade do poder e a colonialidade do saber quando se evidencia o combate aos sujeitos (negros e afrodescendentes) e seus símbolos culturais como não lugar de construção de conhecimento.

Portanto, a colonialidade do imaginário do tremor e do barulhamento da própria paisagem é uma luta constante que se impõem na filosofia africana como filopoética. A aniquilação ontológica, sendo esta uma expressão do epistemicídio (MALDONADOTORRES, 2010, RAMOSE, 2011, e CARNEIRO,2005) e semiocídio cultural (SODRÉ, 1983), é legitimada pelo imaginário.

Para problematizar o imaginário colonizado, tem-se como proposta o percurso de relacionar as paisagens filosóficas africanas como filopoéticas no intuito de disputar os imaginários, de traçar itinerários, rotas na conexão com o todo-mundo. A filopoética da libertação busca habitar a própria paisagem na defesa da criação de conceitos, como lugar da filosofia, mas buscando ultrapassar apenas a criação do conceito, pois essa também tem a função de povoar o imaginário.

Isto é, a filopoética dá-se na tensão crítica e criativa da criação de conceitos e a luta constante de povoar os imaginários. Neste sentido, ser habitado pelas paisagens promovidas pelas filosofias africanas é um eco-mundo em que coloca o espaço europeu e estadunidense como centro do mundo. A insistência por projetos políticos de aniquilamento de outras vozes e o apagamento do diverso das paisagens é a tradução do eco do imaginário do racismo. Isto é, a vitória da poética do genocídio como uma redução do imaginário do mundo traduzido na lógica do desenvolvimento que tem a "episteme dos tempos modernos" (SARR, 2019, p.22) traduzida nas palavras-chave, como o “Progresso, Razão, Crescimento e Ordem" (SARR, 2019, p.22).

Os grupos humanos, os quais foram lidos pelo pensamento da colonialidade têm como leitmotiv a totalidade de uma paisagem. Neste aspecto, a transparência do território político, cultural, histórico e econômico lê os grupos humanos fora de sua paisagem como subdesenvolvido, inferior e não humanos.

A filosofia, que tem na sua tradição o pensamento colonial, mata a potência diversa da imaginação. A filosofia marcada pela colonialidade tem a trapaça de olhar si mesmo pelo fluxo e refluxo do outro. A transparência do centro europeu e, mais recentemente estadunidense, reduz o imaginário do mundo e obriga os territórios diversos a pensarem da mesma maneira a política, a economia e a existência. 
Neste sentido, a filopoética da libertação tem como objetivo provocar outras paisagens nos arquipélagos da filosofia. O deslocamento do espaço-tempo promove a potência da explosão do potencial de imaginação da paisagem filosófica outra. A paisagem filosófica africana: a filopoética como libertação pode vir a explodir o mesmo, entendido aqui como transparência.

A filopoética como entendida neste artigo está em diálogo com as filosofias negroafricanas, com a poética e a filosofia da relação de Édouard Glissant. A discussão da filopoética toma como referência Manuel Norvat em Le Chant du Divers. Introduction à la philopoétique d'Édouard Glissant (2015) ${ }^{3}$. O conceito de filopoética não é cunhado por Glissant, no entanto, percorre seu pensamento. Além do diálogo com Glissant, o texto estabelece um debate com uma filosofia desde a geopoética de África. A paisagem desde África descreve a relação geopolítica e geocultural do texto. $\mathrm{O}$ imaginário, o qual mobiliza a política, a epistemologia e a ontologia do texto, parte do plano de imanência africano e afrodescendente. É a partir da paisagem africana que defendemos a "renovação do imaginário" (SARR, 2019).

No livro Filosofia da Ancestralidade: corpo e mito na filosofia da educação brasileira, Oliveira (2007) apresenta a dinâmica da cultura africana/imaginários sendo reinventada a partir da Ancestralidade. Segundo Eduardo Oliveira:

A ancestralidade é o elemento mais importante da denominada cosmovisão africana. Segundo minha análise de Marco Aurélio Luz (1995), Ronilda Ribeiro (1996) e Fábio Leite (1984) a ancestralidade concomitantemente compõe e manifesta a expressão visível da "dinâmica civilizatória africana". Esta dinâmica civilizatória africana foi engendrada pela cosmovisão africana, que por sua vez está ancorada na ancestralidade. A ancestralidade, assim, passa a ser o principal referencial para o negro brasileiro tanto na vivência profana quanto na experiência religiosa - (experiência do sagrado, diria Bastide) (OLIVEIRA, 2007, p. 182).

Oliveira (2007) apresenta a ancestralidade como uma categoria que preserva e atualiza a cosmopercepção africana no Brasil. A ancestralidade guarda o princípio fundante para o mito e o rito da continuidade negro-africana.

O texto defende um contexto do debate e das questões pertinentes na disputa por um filosofar desde a geopoética africana. A defesa pelas paisagens africanas, na disputa da guerra dos imaginários, potencializa uma filosofia que povoa o imaginário e alimenta

\footnotetext{
${ }^{3}$ Este livro foi objeto de tese defendida em 21 de março de 2013, em Sorbone. A tese foi intitulada:
} L'expression du Divers dans la philopoétique d'Édouard Glissant.. 
o debate de uma filosofia decolonial, isto é, uma filosofia africana crítica. Portanto, defende-se a necessidade de filosofara partir do eco do imaginário africano e a necessidade que tem de um pensar a partir da paisagem reinventada no barulhamento e no tremor negro-africano. Ou seja, disputa-se a guerra do imaginário na perspectiva da filopoética da libertação.

\section{FILOSOFAR DESDE A GEOPOÉTICA AFRICANA}

A discussão em torno do pensamento filosófico desde África estabelece uma crise ao entendimento de um fluxo de caminhar na trilha do fazer filosófico, apenas a partir de uma paisagem como imagem do pensamento: as paisagens europeias e, mais recentemente, estadunidenses. A geopolítica do conhecimento é determinante para a legitimidade dos territórios.

Ao inserir o debate de África como território da filosofia, já desloca o imaginário congelado do pensamento, pois esta falta de movimento condiciona apenas uma paisagem como imagem do pensamento. O imaginário reduzido é atualizado pela lógica da colonialidade que atualiza formas de ser, pensar e dominar de uma racionalidade que persiste na trilha da transparência.

A colonialidade é produzida pela tripla ação, pois ela opera a partir da colonialidade do ser, colonialidade do poder e colonialidade do saber. É uma colonização ontológica, política e epistemológica. E, nesta operação semiótica, desdobra-se uma política do desejo, a qual legitima o terror e o horror do cenário de um imaginário pouco ampliado para as abordagens múltiplas acerca da filosofia.

A ampliação do imaginário acerca da filosofia coloca o debate acerca da descolonização como uma constante na disputa pela vida nos debates acerca das filosofias africanas. A filosofia africana insere-se na crítica da colonização. "A maior parte dos teóricos pós-colonialistas continuaram a reivindicar a descolonização da mente" (MASOLO, 2010, p.330). A tripla colonialidade (poder, saber e ser) ${ }^{4}$ teve como destino a vida. A “colonialidade da vida" (FLOR DO NASCIMENTO, 2010).

\footnotetext{
${ }^{4}$ A discussão está em diálogo com autores como Nelson Maldonado-Torres: A topologia do ser e a geopolítica do conhecimento. Modernidade, império e colonialidade (2010). Anibal Quijano: Colonialidade do poder e classificação social (2010). Ramón Gorsfoguel: Para descolonizar os estudos da economia política e dos estudos pós-coloniais: transmodernidade, pensamento de fronteiras e colonialidades global (2010). CASTRO-GÓMEZ, Santiago:Critica de la razón latino Americana. (2011).
} 
Flor do Nascimento compreende como colonialidade da vida a fundação da ontologia que construiu a perspectiva de que vidas têm valores dissemelhantes. $\mathrm{O}$ grau de produção de vidas diferentes, as hierarquias das vidas, a percepção de que a ontologia da vida hierarquizada constrói o entendimento de que vive e que morre. $\mathrm{O}$ fundamento deste entendimento dá-se desde a perspectiva do racismo. $\mathrm{O}$ que fundamenta esta perspectiva filosófica é a origem estática, a essência e o desejo obstinado do uno e do absoluto totalitário que percorrem as paisagens filosóficas colonizadas.

As produções filosóficas agenciadas pela violência da colonialidade produzem vidas colonizadas. Em diálogo com Flor do Nascimento (2010), este afirma que "A colonialidade da vida normalmente tem sido usada como pretexto para práticas violentas contra sociedades" (FLOR DO NASCIMENTO, 2010, p.114). A prática da colonialidade tem a intenção de legitimar a colonialidade do poder sobre o ser, ou seja, produzindo, portanto, uma colonialidade do ser.

Filosofar desde África problematiza o tempo, o espaço e as paisagens das narrativas filosóficas congeladas pela perspectiva "ocidentocêntrico". O fato de experimentar o deslocamento da paisagem do pensamento já problematizaa paisagem do projeto eurocêntrico e estadunidense. O espaço “ocidentocêntrico", segundo (Oyèrónkẹ Oyěwùmí, 1997), é a expressão dos estudos africanos que foram marcados pelos projetos políticos e culturais eurocêntricos e estadunidense. O espaço "ocidentocêntrico" movimenta a "colonialidade da vida" (FLOR DO NASCIMENTO, 2010) negra como um projeto do imaginário.

Este projeto é a tradução de uma perspectiva do tempo moderno europeu. $\mathrm{O}$ discurso filosófico moderno europeu compreendia os povos fora do sistema-mundo europeu como homens no estado de natureza e que ainda não tinham a tingido o estado de sociedade. O discurso moderno ocidental era constituído de uma anticultura, que, segundo Glissant (2011, p. 187), “esforça-se por garantir a vitalidade aberta do choque de culturas. Tratar-se-á de um regresso à barbárie ou de uma preocupação profética contra a barbárie da redução e do uniforme?". A violência moderna ocidental é o desejo da barbárie e a unidade cultural. A poética do genocídio é uma lógica presente na cultura moderna ocidental. Em diálogo com Flor do Nascimento, acerca da modernidade:

O modo hegemônico de lidarmos com as práticas sociais, com a política, com a ética e com o conhecimento em nosso cotidiano e nas ciências é um modo, sobremaneira, moderno; e, assim sendo, partilha de uma série de características desta mesma Modernidade que o faz nascer e funcionar. É na Modernidade que 
vemos surgir um específico modo de exercício de poder, que tem uma determinada maneira de articular conhecimentos para a validação desse modo de exercê-lo, fundado em uma geopolítica, que indica que esses modos de produção de conhecimento e de exercício de poder têm um local privilegiado de irradiação e atuam de modos diferentes em diferentes lugares do mundo (FLOR DO NASCIMENTO, 2010, p.20).

A obstinada vontade do uno e a persistência em aniquilar o diverso têm sua legitimidade e universalização no alinhamento político, econômico e ético da modernidade. Neste aspecto, uma das críticas das filosofias negro-africanas está no combate à herança da colonialidade, que se expressa pelo racismo. A tensão estabelecida com o eco da colonialidade provoca o entendimento de "que a vida é um combate interminável” (FANON, Frantz, 2010, p.111).

A ação tripla da colonialidade (poder, ser e saber) da vida é uma imagem que a filosofia negro-africana se contrapõe. Os agentes que se identificam com o horizonte de ação da produção da filosofia negro-africana produzem o conhecimento na crítica ao (TORRES, 2010; RAMOSE, 2011; CARNEIRO,2005) e semiocídio cultural (SODRÉ, 1983).

A mentalidade moderna acerca de África tem sua produção desde um projeto político e cultural que aniquila os símbolos africanos como aquele que dá o que pensar é marcadamente racista, que delega à África o atraso responsabilizado pela "raça negra". É necessária uma desconstrução das ciências coloniais, como Mudimbe (2013a) salienta, chamando a atenção para a desmitificação do que se tem entendido acerca do continente africano. E esta nova visada teria o objetivo de uma reinterpretação da filosofia negroafricana com mais critério acerca da criticidade. Ramose (2011), no texto Sobre a Legitimidade e o Estudo da Filosofia Africana, apresenta os dois pilares de dúvidas acerca dos estudos africanos, a razão e a fé, semelhante a Mudimbe (2013a), que problematiza o fundamento religioso (a fé no Deus de Jesus Cristo) e a razão - como as duas perspectivas que fundamentam o combate as formas e os conteúdos do filosofar africano de pensar sobre si próprio.

A tentativa de retirada de pensar desde a própria paisagem africana tem no racismo seu fundamento. $\mathrm{O}$ espaço e tempo africano foram negados na construção da filosofia. $\mathrm{O}$ combate ao tempo (lê-se: história) e ao espaço (lê-se: antropologia) africanos foram um fator de muita força para a constância da violência racial aos territórios negros/africanos. Valentin Yves Mudimbe (2013a) apresenta no livro A invenção da África - Gnose, Filosofia e a Ordem do conhecimento, uma abordagem a qual problematiza as paisagens 
ocidentalizadas acerca de África. Os discursos imperiais sobre África produzidos a partir dos missionários religiosos, antropólogos e filósofos são desconstruídas por Yves Mudimbe (2013a).

Mudimbe (2013a) defende que esta estrutura de pensamento colonial inventou a África, e esta invenção foi produzida à luz do semiocídio cultural e do epistemicídio. Sendo essa uma construção europeia, a que transformou o espaço físico, integrou as histórias econômicas locais ao sistema totalitário europeu, na lógica de um sistema de pensamento dicotômico; o oral versus escrito, tradicional versus moderno, as comunidades agrícolas versus civilização urbana. Mudimbe (2013a) entende que o imaginário moderno é produtor da colonialidade acerca da invenção das Áfricas e dos africanos. Entretanto, o filósofo congolês, Mudimbe, disputa a interpretação da paisagem sobre a filosofia africana. Valetin Yves Mudimbe (2013a) compreende as correntes presente na filosofia africana como "filosofias primitivas", a etnofilosofia, a antietnofilosofia, a personalidade africana, a perspectiva hermenêutica e a semiologia. Os estudos africanos, como sinalizado por Mudimbe em $A$ invenção de África. Gnose, filosofia e a ordem do conhecimento (2013a) e em A Ideia de África(2013b), questionam a disputa pela interpretação acerca de África ser uma invenção do Ocidente colonial.

A paisagem a qual o Ocidente colonialista mobiliza na geração dos filósofos africanos chamados de críticos é da aniquilação da diferença ou da exotização desta. $\mathrm{O}$ filósofo Marcien Towa (2015) denomina o ocidente como "o ocidente imperialista, inimigo do pensamento" (TOWA, 2015, p. 65). O filósofo compreende que o Ocidente moderno não seria o responsável pela universalização da razão, mas, pelo contrário, ele seria aquele que limita a extensão desta razão. Segundo Towa (2015):

Não é o culto, mas a traição ao pensamento, que é necessário condenar na civilização ocidental; o Ocidente não é culpado pela extensão e pela universalização da razão, mas, sim, pela sua limitação criminal. Como já falamos, o pensamento, a razão, não existe: o que existe são apenas homens pensantes e racionais, ou capazes de pensamento e de razão. É através do pensamento que o homem afirma sua liberdade, sua força e sua superioridade sobre todos os seres conhecidos. Estabelecendo sobre os operários e os povos do Terceiro Mundo um sistema de exploração e de opressão, a burguesia ocidental organiza, dessa maneira, o sufocamento do pensamento e da razão da maioria da humanidade. A lógica da dominação leva a burguesia internacional a se aliar às potências retrógadas que ela mesma teve que combater para se emancipar (o fanatismo, a superstição etc...) e a se opor à expansão do pensamento entre suas vítimas, porque o pensamento destas só pode se voltar contra a opressão. O Ocidente empreende a falsificação sistemática da história e da cultura dos povos dominados com o objetivo de justificar a dominação. A desumanização dos povos 
dominados - que é, na realidade, o resultado da opressão -, vem a ser, desse ponto de vista, a razão da dominação e da exploração. Tal empreendimento de falsificação constitui uma grave violação da objetividade cientifica e da razão (TOWA, 2015, p. 65-66).

Towa (2015), ao fazer a crítica ao Ocidente imperialista, chama atenção para a espacialidade determinante e homogeneizadora do Ocidente sobre a disputa pela produção africana de conhecimento. Os estudos africanos são denominados de ocidentocêntricos (Oyèrónkẹ Oyěwùmí, 1997), pelo fato de o Ocidente persistir na ordem dos discursos e das passagens sobre o continente africano.

A disputa pela produção da paisagem de África atravessa o debate da disputa pela filosofia africana. O filósofo beninense Paulin Hountondji constrói uma crítica ao discurso ocidental colonialista sobre a filosofia africana, este debate aparece no livro Philosphpy African: Mity \& Reality.

Paulon Hountondji (2010) apresenta duas perspectivas sobre os estudos africanos. Primeiro se tem aquele que tem o conhecimento de África e segundo o conhecimento de africanos. O objetivo comum dessas duas abordagens é a África. O conhecimento de África seria os intelectuais da etnofilosofia. Estes representam a reconstituição da visão comum dos antepassados ou as finalidades coletivas das sociedades africanas. A etnofilosofia tem uma ideia presente de uma total unanimidade, na qual todas as pessoas presentes na sociedade concordavam mutuamente.

Tendo apresentado a problematização da perspectiva ocidental, da produção das paisagens acerca de África, de Paulin Hountondji, Valentin Yves Mudimbe, Marcien Towa, estes reivindicam para a filosofia alegitimidade em interpretar-se.

Portanto, na filosofia negro-africana, seus agentes estão produzindo conhecimento na crítica da violência da razão, isto é, do epistemicídio e do semiocídio cultural, no enfrentamento dos movimentos econômicos, históricos e políticos que marcaram a compreensão da filosofia política moderna ocidental, fundamentada pela perspectiva da negação da alteridade: a colonialidade. Segundo Julvan Oliveira e Sergio Nascimento (2016):

O debate sobre a filosofia africana leva-nos a descontruir o processo de colonização da África e as perspectivas dos pensamentos pós-coloniais comprometidos com a preservação das culturas africanas e das identidades diaspóricas, assim como e os requisitos para a identificação dos conhecimentos tradicionais ou endógenos e sua integração nos vários programas educacionais ou

${ }^{5}$ Valentin Yves Mudimbe (2013a) considera o livro do Hountondji a "bíblia" da etnofilosofia. 


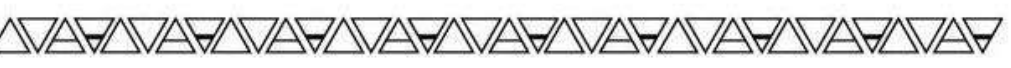

programas específicos nas escolas e universidades. (NASCIMENO; OLIVIERIA, 2016, p.14).

Filosofar desde a geopoética africana insere a filosofia negro-africana com o compromisso com a liberdade. A máxima da libertação é colocada em destaque nos movimentos críticos em que a filosofia africana está inserida. O horizonte filosófico negro-africano está a agenciado com a afirmação dos corpos vitimados pelo "sistemamundo"colonialista. Segundo Marcien Towa (2015): “O desafio consiste em opor uma resistência eficaz à mistificação ideológica do imperialismo e da opressão e de evitar toda cumplicidade, consciente e inconsciente, com a dominação, pois o destino da filosofia está ligado ao da liberdade" (TOWA, 2015, p. 28).

A virada epistemológica, a crítica a tripla colonialidade (poder, ser e saber), a ética de afirmação das vítimas (alteridade), o direito à interpretação autônoma, a construção de uma filosofia própria desde as suas paisagens e o compromisso com a liberdade, são alguns dos horizontes de ação da filosofia negro-africana.

\section{ECO DO IMAGINÁRIO FILOSÓFICO AFRICANO: HABITAR E SER HABITADO PELA PRÓPRIA PAISAGEM}

A filosofia africana tem problematizado na sua historiografia a importância de localizar-se a partir de sua paisagem. A luta constante pela legitimidade em interpretarse é evidenciado por exemplo pela problematização em que Valentin Yves Mudimbe realiza acerca da visão de África no livro $A$ invenção de África. Gnose, filosofia e a ordem do conhecimento (2013a) e em A Ideia de África (2013 b) problematizam a disputa pela produção do imaginário acerca de África.

A produção filosófica marcada pela colonialidade da política, da epistemologia e da ontologia sobre os territórios e corpos africanos e latino-americano exigiu produziu uma relação necessária dos grupos negros/africanos e ameríndios terem como produção decolonial e crítico está imerso em suas paisagens. O movimento de ser educado a captar o eco do lugar, sentir e ser penetrados nos seus poros pelas paisagens que te habitam é um processo próprio do filósofo que está no horizonte da libertação crítica ao projeto de colonialidade. Portanto, o eco do imaginário filosófico africano tem como leitmotiv o direito à vida. A luta por justiça e libertação, isto é, a superação da lógica de opressão. 
E uma das opressões operadas pelo projeto de colonialidade foi produzir um aniquilamento da beleza da paisagem dos povos "subalternizados". A paisagem aqui é entendida como aquela que mobiliza o imaginário. Segundo Luís Ferreira dos Santos (2019):

\begin{abstract}
A paisagem está relacionada com o imaginário. E a insurreição do imaginário (recusa em morrer) é o lugar da filopoética no enfrentamento da fixidez do barco negreiro, em que a razão de ser é um ato para a morte. A paisagem é compreendida por Milton Santos (2002) como aquela que relaciona os objetos do presente e do passado, todavia, o espaço é sempre o presente. A paisagem apenas não se vê, ela tem cheiro e se sente. A paisagem é mobilizadora do engajamento, da potencialidade política. A paisagem potencializa o imaginário. A ampliação do imaginário provoca a mudança na relação com o mundo [...] (SANTOS, 2019, p.161).
\end{abstract}

A paisagem é território e territorialidade. Ela é o passado, presente e tem horizonte para o futuro, enquanto o espaço se relaciona com o presente, a paisagem mobiliza o passado e o presente. Ela é a potência do imaginário. Na paisagem, encontra-se o lugar da possiblidade de construção para a crítica aos projetos de colonialidades. É uma resposta à violência da miséria.

A geopoética de pensar desde a paisagem africana mobiliza o fluxo contínuo de "uma renovação das fontes dos imaginários [...]” (SARR, 2019, p.111). E esta renovação dáse pela relação mediada pela natureza. O eco do imaginário filosófico africano de habitar e ser habitado pela própria paisagem tem seu caminho mediado pela experiência dos “imaginários guerreiros” (SANTOS, 2019, p. 178). Os imaginários guerreiros são representados pelos elementos da natureza, tais como a floresta, a terra, o fogo, o vento. Estes são elementos que estão presentes na cosmopercepção do candomblé. Segundo Santos (2019):

Na cosmopercepção do candomblé diaspórico, os elementos da natureza são sagrados. A natureza atua neste aspecto como um a priori na ação política da recusa em morrer. Os imaginárioss africanos, em deriva na diaspóra, trazem elementos de resistência, o qual atualiza as forças poéticas do ciclo da vida. A partir da natureza, a cosmopercepção africana na diaspória recriou formas de resistências nos arquipérlagos: os quilombos, as religiões de matrizes africanas, os cursinhos pré-vestibulares negros, as irmandades negras são ações políticas contra o deus do abismo, o Abadon (SANTOS, 2019, p.178-179).

A poética de experimentar e vivenciar os imaginários africanos reinventados e reelaboradas na diáspora é um ato político que segue na contramão da perspectiva da “colonialidade da vida". As paisagens relacionam o ato político e poético na produção de sentidos na desobediência de caminhar na paisagem colonizada, a qual aniquila o diverso 
e a exaltação da vida que não segue o modelo hegemônico. Neste caso, ser habitado pela própria terra é uma forma de reinventar outros imaginários a partir das próprias paisagens: este é um ato poético de insubordinação ao eco do imaginário da redução da vida. $\mathrm{O}$ eco do imaginário filosófico africano mobiliza uma política da paisagem com compromisso com a ampliação da vida. Ou seja, "A política da paisagem é uma poética” (SANTOS, 2019, p.214).

É importante não perder o entendimento de que a paisagem que está no plano de imanência desta política não tem apenas a compreensão do espaço/lugar, ou seja, da geografia. O primeiro do pensamento é paisagem, pois é o lugar do imaginário (SANTOS, 2019).

O pensamento, quando se desloca sem paisagem, recai no totalitarismo de impor sua paisagem para todas as territorialidades com as quais se relaciona. O projeto de um pensamento sem paisagem recai no pensamento da colonialidade que busca impor um único imaginário como mobilizador da potência da vida. Neste aspecto, não existe liberdade. A vida é codificada por uma paisagem que busca aniquilar o diverso. Não tem o exercício de habitar e ser habitado pela própria territorialidade.

É uma luta constante a disputa pela paisagem que foi codificação pela lógica da colonialidade. É uma caminhada na tentativa de forjar não apenas os sistemas, mas as condições culturais pelos os sistemas são forjados. Segundo Sarr (2019):

Os sistemas sociais, políticos e educativos podem mudar em cinquenta anos: foi o caso da África colonial. Mas os sistemas de pensamento, as visões de mundo, os enquadramentos epistêmicos oriundos das culturas africanas, assim como a profunda filosofia da vida que eles veiculam, estão longe de ter cessado de acionar as sociedades africanas (SARR, 2019, p.117).

O caminho que Sarr (2019) propõe é de uma crítica e deslocamento dos pensamentos de sistema e de uma imersão nas culturas africanas como aquela mobilizadora do pensamento. Neste sentido, é o mesmo que dizer da paisagem como mobilizadora de outros imaginários na produção de sentidos dos territórios. Segundo Santos (2019):

A paisagem, por ser um geopensamento, desloca-se dos pensamentos de sistema e dos sistemas de pensamento. A paisagem do pensamento do tremor estende-se infinitamente como um conjunto de pássaros difícil de ser numerável, das asas semeadas do sal negro da terra. O pensamento do tremor reúne da absoluta diversidade, em um turbilhão de encontros. É uma utopia que não se fixa e que 
abre o amanhã, assim como o sol e um fruto compartilhado (SANTOS, 2019, p. 161).

A paisagem mobiliza a insurreição do imaginário. Movimenta projetos utópicos com a dimensão poética de se relacionar com a "todo-o-mundo" (GLISSANT, 2011). No entanto, esta relação com o todo-o-mundo acontece com a constância de ser habitado pela própria paisagem, ou seja, na diferença de cada lugar, que existe a possibilidade de relaciona-se com o todo-o-mundo.

A paisagem afrobrasieira que atualiza o eco do imaignário africano tem a força poética da resistência e a beleza do barulhamento do lugar.A paisagem do lugar é produtora de sentido na criação de uma "totalidade-mundo" aberta.

A imersão na paisagem, ou seja, conectar-se com o eco do imaginário filosófico africano insere a produção filosófica africana na disputa pela ampliação de projetos de vidas. E, para isso, está reconectado com o tremor imprevisível das paisagens que sofreram a violência colonial, estabelece a dimensão política e ética da filosofia da paisagem: a relação da política com a poética.

A paisagem está intrinsicamente relacionada com a natureza. A paisagem marca a diferença e possibilita a reconexão com o "todo-o-mundo". Na paisagem, está a memória, a história e o esquecimento. A paisagem é a fonte de imagem, a possibilidade de ser uma fonte diversa, pois cada lugar é habitado por suas paisagens. As paisagens habitam as poéticas. E a partir dessa imanência se produz as políticas. Portanto, as políticas estão de mãos dadas com a poéticas, nesse fluxo argumentativo.

A filosofia, neste aspecto, dialoga de maneira direta com a poética. Pois se compreende que o projeto colonialista (poder, ser, saber) tem como potência de emergência um projeto poético como mobilizador da sua ação. Há uma guerra de imaginários e esta é mobilizadora de projetos utópicos. Neste sentido, adentramos nessa disputa com a filopoética.

\section{FILOPOÉTICA DA LIBERTAÇÃO}

A filopoética (NORVAT, 2015) é forjada em relação com a filosofia negroafricana e com a poética da Relação de Édouard Glissant $(2011,2009)$. "A poética da Relação, nesse sentido, é uma paisagem 'contra-moderna', ela recusa em morrer"(SANTOS, 2019, p. 91). O debate em torno da filopoética está em diálogo com 
Manuel Norvat (2015), no livro Le Chant du Divers. Introduction à la philopoétique d'Édouard Glissant.

A filosofia africana apresenta uma multiplicidade de visões de mundo, tem um diverso de paisagens que movimenta o fazer filosófico. O projeto colonialista de aniquilamento da diferença, que se atualiza por meio de uma poética do genocídio, defende a ideia de que a afirmação da sua vida, contraditoriamente, dá-se com a morte do Outro. O eco do imaginário do racismo é a potência da poética do genocídio.

Na contraposição dessa ideologia, de um inimigo absoluto, produzido pelo projeto colonialista moderno, a filopoética da libertação busca disputar essa guerra de imaginários. Na guerra de imaginário da lógica da necropolítica,o destino da poética do genocídio é de "fazer morrer e deixar morrer" (MBEMBE, 2018).O imaginário da necropolítica é uma forma de subjugar as vidas ao poder de morte. A produção desejante do necropoder cria "mundos de mortes". O imaginário dos povos violentados pela colonialidade, a qual perpetua nos dias atuais pelo signo da necropolítica, é alimentado por alienações reais. Na leitura de Jaime Amparo:

De acordo com Mbembe, a articulação entre velhas e novas formas de dominação está fazendo surgir uma nova forma de governamentalidade cuja característica principal é a sujeição da vida ao poder máximo da morte. Neste contexto de necropoder, alguns territórios ambientam a "topografia da crueldade" e algumas populações figuram como os marcados incondicionalmente como passíveis de serem mortos. Neste novo paradigma, a distribuição calculada da morte é o que configura a (necro)política moderna (AMPARO, 2011, p. 6).

A necropolítica é uma expressão do imaginário. O projeto da necropolítica tem como fluxo desejante a atualização da "colonialidade da vida", esta evidencia de maneira primeira a derrota da filosofia, é o seu antipensamento, pois coloca o sofrimento e o infortúnio como condição para produção de outro mundo, é uma filsoofia contra a vida. É contra a natureza. O imaginário filosófico que legitima os projetos de colonialidade tem como paisagem uma estética de embrutecimento da sensibilidade.

O trabalho primoroso da filósofa Nathalie Etoke (2010) problematiza uma paisagem que evidencia uma estética desde a "melancolia africana":

Esthétique du malheur et de la soufrrance confrontée au refus de mourir, la melancholie africana est un concept extensible qui examine comment les Subsahariens et les Afrodescendants gèrent la perte, le deuil et la survie dans une pratique du quotidien contaminé par le passé (ETOKE, 2010, p. 27). 
O infortúnio e o sofrimento, assim como o banzo, a saudade é a potência para a insurreição e renovação dos imaginários. Uma violência causado pelos projetos racistas, paradoxalmente, pode vir ser ressignificado como ferramenta para a "recusa em morrer".

E a recusa em morrer dá-se na urgência e necessidade de filosofar, produzindo conceitos e fecundando de imaginário (filopoética). Portanto, umas das ações do filósofo e da filósofa se dá não em criar conceitos apenas, mas de fecundá-los de imaginação.

A paisagem tem papel imprescindível nesta fecundação de imaginação, é a morada da fonte e renovação de imaginário. Com isso, a filopoética busca, neste caminho de fecundar o imaginário, a superação e crítica à dominação da colonialidade.

A filopoética relaciona a filosofia com a poesia, a estética com a política, na crítica a violência colonialista. A perspectiva do imaginário da colonialidade impõe o obstinado desejo de congelar e violentar o diverso. A filopoética está na disputa por imaginários no desejo constante de reinventar o tempo de horror e terror.

A libertação é o destino da filopoética, ela tem o diverso como movimento constante, na contraposição ao sentido da unidade redutora. A filopoética tem como princípio o diverso do mundo, porque é habitado e habita a sua paisagem. Pois, desde o seu lugar, é possível estabelecer a relação com "todo-o-mundo" (GLISSANT, 2011).

A filopoética não cai na armadilha epistemológica de defender uma filosofia sem paisagem, não recai no movimento unitário e totalitário do pensamento sem universal. A armadilha explicitada legitima e autoriza o projeto genocida do imaginário único. A arbitrariedade do imaginário redutor sensibiliza a aniquilamento da vida. A redução do diverso da existência.

Na compreensão da filopoética, segundo Santos (2019):

A filopoética afrodiaspórica busca fazer a crítica à modelagem de pensamento que é fundamentado na transparência, na unidade, no continente, ou seja, nos sistemas de pensamentos traduzidos pela herança da Ideia. $\mathrm{O}$ arquipélago, categoria trazida do diálogo com Glissant, vai na contramão da herança da Ideia (continente): ele atua como as partes para o "Todo-o-Mundo". É a possiblidade da abertura do mundo para a multiplicidade (SANTOS, 2019, p.20).

A filopoética, por buscar a abertura para o diverso, tenta não recair na lógica da transparência, a qual cria o outro como a sua própria semelhança. Em contraposição à transparência, a filopoética recorre à opacidade, como potência, para a relação com o outro, a partir da opacidade, não da transparência. A opacidade estabelece o debate ética na filopoética: a relação com o outro como outro, não como projeção daquele que tem o 
poder do discurso. A opacidade livra dos totalitarismos e dos relativismos exacerbados. A opacidade segue na contramão da transparência, que tem a unidade e a fixidez do pensamento com sentido do real. Todavia, a opacidade segue no sentido contrário: é pelo diverso que movimento o pensamento da opacidade. O conceito de arquipélago é cunhado nas obras de Édouard Glissant na contraposição ao conceito de continente. O arquipélago estabelece o diverso enquanto o continente determina a unidade redutora.

Uma outra ideia que aparece é do continente versus o arquipélago na discussão acerca da filopoética. O continente busca generalizar sua paisagem para todos os lugares em que ele se relaciona. O que existe é uma relação em repouso, entretanto com o arquipélago é uma relação em movimento. Segundo Glissant acerca do debate sobre o continente e o arquipélago: $\mathrm{O}$ "pensamento continental, que desvela em diásporas os esplendores do Uno. Pensamento arquipelágico, onde se concentra a infinita variação da diversidade. Mas a aliança entre eles está ainda por vir" (GLISSANT, 2014, p.219). O arquipélago tem sua contraposição estabelecida pelo pensamento continente, que possui apenas uma paisagem como imagem. No arquipélago, existe a possiblidade do diverso de paisagem. O arquipélago possibilita a multiplicidade, consequentemente, a possiblidade da relação com o Todo-mundo.

A filopoética da libertação tem nos arquipélagos o sentido de filosofar, pois eles são diversos, heterógenos e segue na lógica da imprevisibilidade. $\mathrm{O}$ arquipélago não é simplesmente o espaço, pois, primeiramente, é imaginário, ele é permeado pela paisagem. O que mobiliza o pensamento no entendimento do arquipélago também é a paisagem.

As paisagens, na filopoética da libertação, caracterizam a geopoética, isto é, o eco do imaginário, o qual mobiliza a poética do lugar. A geopoética traz a política e a cultura de maneira intrínseca na renovação do imaginário.

A filopoética da libertação na relaçãoentre a filosofia negro-africana e a poética da relaçãoinstaura a necessidade de renovação do imaginário. Para isso, a filopoética busca reconstruir a memória, tem a necessidade manter a memória viva. Pois os "corpos e memória multiladas" (KISUKIDI, 2017, p.67) são combatidas e aniquiladas pelo projeto da colonialidade, portanto, faz-se urgente e necessária a disputa acerca dela.

Uma outra questão que caracteriza a filopoética da libertação é a atitude crítica ao imaginário racista. O racismo é um elemento que mobiliza a política da colonialidade. $\mathrm{E}$, por fim, a sua característica de ser interdisciplinar e complexa. As tensões disciplinares são mobilizadoras para qualificar a ação da filopoética. 


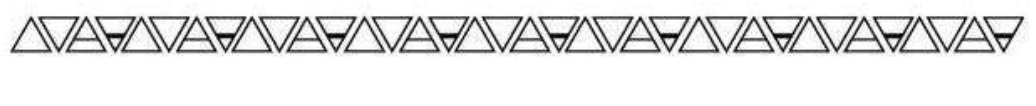

\section{CONCLUSÃO}

O presente texto, Paisagens filosóficas africanas: filopoética da libertação como disputa de imaginário, provocou a importância do debate do diverso na produção filosófica. O artigo, na tentativa de apresentar a chave de leitura filopoética da libertação, relacionou os debates em torno da filosofia negro-africana com a poética da relação. Para isso, agenciou os debates em torno dos conceitos de paisagens, opacidade, transparência, arquipélagos e continente e imaginário.

A disputa por imaginários é o plano de imanência das paisagens filopéticas em movimento no texto. A filopoética defende a criação de conceitos, mas além de criar conceitos, a filopoética também tem a função de povoar o imaginário.

O texto seguiu, no primeiro momento, o caminho de apresentar uma perspectiva de filosofar desde a geopoética africana. As paisagens africanas foram mobilizadoras do argumento nesta seção. A filosofia negro-africana estabelece uma cisão no imaginário reduzido de que a filosofia somente tem uma paisagem. A fixidez do sistema de pensamento que tem o pensamento sem imagem produz um imaginário reduzido. Entretanto, ao trazer a paisagem desde África como território da filosofia mobiliza o imaginário reduzido apenas da Europa e do território estadunidense como detentores do discurso filosófico. A ausência do diverso no pensamento movimenta uma imagem do pensamento sem exultar uma vida diversa. O imaginário reduzido, pouco ampliado, legitima a lógica da tripla colonialidade (ser, poder e saber). A filosofia negro-africana potencializa o pensamento decolonial e alimenta a crítica como leitmotiv.

$\mathrm{Na}$ segunda seção, apresentou a discussão do eco do imaginário filosófico africano: habitar e ser habitado pela própria paisagem. A paisagem é mobilizadora do imaginário, pois, diferente do espaço que está com a seta para o presente, a paisagem mobiliza o presente e o passado. A paisagem é fonte do imaginário. $\mathrm{O}$ imaginário é renovado pelo barulhamento e tremor das paisagens.

E, por fim, a filopoética da libertação como filosofia africana. A filopoética relaciona-se com a filosofia negro-africana e com a poética da relação. A filopoética insere-se na disputa da guerra de imaginários. Esta guerra é em torno da disputa de paisagens. É uma guerra de imaginários. A luta pelo imaginário é um campo pela disputa 
de vida. Para isso, busca o diálogo comas paisagens de cada lugar com pretensões de se relacionar com o "todo-o-mundo".

A filopoética da libertação tem como sentido a crítica à poética do genocídio, que tem sua fonte renovada pelo imaginário do racismo. A violência racial, potencializada pelo imaginário, retira os grupos humanos subjugados pela colonaliadade do ser, do poder e do saber da partilha do todo-o-mundo. A política do genocídio tem no imaginário da necropolítica a sua legitimidade e educação da sensibilidade. Esta poética desumaniza e tiraniza os grupos humanos que foram retirados da paisagem ocidentalizada.Todavia, o imaginário que mobiliza a filopoética da libertação, o eco do imaginário africano,potencializa a produção de imaginários de resistência a colonialidade da vida.

Filosofar desde a filopoética da libertação impõe como exercício decolonial a renovação do imaginário. Mas um imaginário que tenha a superação da violência, da crítica aos projetos de colonialidade. Um imaginário que seja da defesa da vida e da ampliação do diverso da existência. Portanto, a luta constante pelo imaginário aberto e integrador é um movimento importante para a manutenção da vida.

As Paisagens filosóficas africanas como filopoética da libertação tem a disputa de imaginário como manutenção da civilização e a luta para barrar os projetos que buscam institucionalizar a barbárie. E, para isso, no debate filosófico contemporâneo, na disputa para ampliar o imaginário, filosofar desde África, estar aberto para o eco do imaginário africano é ampliador de outras paisagens para continuar vivo no movimento de espalhar beleza. E filosofar desde a paisagem africana tem como movimento "Dar sentido ao que se vive. Mesmo que o espaço flerte com o absurdo" (MONGA, 2011, p. 56).

\section{REFERÊNCIAS BIBLIOGRÁFICAS}

ALVES, Jaime Amparo. NECROPOLÍTICA RACIAL: A PRODUÇÃO ESPACIAL DA MORTE NA CIDADE DE SÃO PAULO. Revista da Associação Brasileira de Pesquisadores/as Negros/as (ABPN), [S.1.], v. 1, n. 3, p. 89-114, fev. 2011. ISSN 2177-2770. Disponível em: $<$ http://www.abpnrevista.org.br/revista/index.php/revistaabpn1/article/view/276>. Acesso em: 14 dez. 2018.

CASTRO-GÓMEZ, Santiago. Critica de la razón latino Americana. 2. ed. Bogotá: Editorial Pontificia Universidade Javeriano: Instituto Pensar: CONCIENCIAS, 2011.

CARNEIRO, Sueli. A construção do outro como não-ser como fundamento do ser. $2005.339 \mathrm{f}$. Tese (Doutorado em Educação) - Faculdade de Educação, Universidade de São Paulo, São Paulo, 2005.

FANON, Frantz. Os Condenados da Terra. Juiz de Fora: Editora UFJF, 2010. 
. Pele Negra, Máscara Brancas. Salvador: EDUFB, 2008.

FLOR DO NASCIMENTO, Wanderson. Por uma vida descolonizada: diálogos entre a bioética de intervenção e os estudos sobre a colonialidade. 2010. $128 \mathrm{f}$. Tese (Doutorado em Bioética), Universidade de Brasília, Brasília, 2010.

GLISSANT, Édouard. Poética da Relação. Portugal: Porto Editora, 2011. Philosophie de la Relation: poésie en étendue. Éditions Gallimard, 2009.

Gallimard/Editora UFJF, 2014.

$O$ pensamento do tremor. La cohée du Lamentin. Juiz de Fora:

GROSFOGUEL, Ramón. Para descolonizar os estudos de economia política e os estudos póscolonias: transmodernidade, pensamento de fronteiras e colonialidade global. In SANTOS, Boaventura de Sousa; MENESES, Maria Paula (orgs.). Epistemologias do Sul. São Paulo: Cortez, 2010, pp. 455-491.

HOUNTONDJI, Paulin. African philosophy: myth and reality. Indiana University Press. Bloomington and Indianapolis, 1983.

KISUKIDI, Nadia Yala. Lettia Africana: philosophie, décolonisation et mélancolie. In: Achille Mbembe et Felwine Sarr. Écrire l'Afrique-Monde. Les Ateliers de la pensée. Paris: Phillippe Rey. Dakar: Jimsaan, 2017.

MALDONADO-TORRES, Nelson. A topologia do ser e a geopolitica do conhecimento. Modernidade, império e colonialidade. In SANTOS, Boaventura de Sousa; MENESES, Maria Paula (orgs.). Epistemologias do Sul. São Paulo: Cortez, 2010, pp.196-443.

MASOLO, Dismas. Filosofia e Conhecimento Indigena: uma perspectiva africana. In SANTOS, Boaventura de Sousa; MENESES, Maria Paula (orgs.). Epistemologias do Sul. São Paulo: Cortez, 2010, pp. 313-337.

MBEMBE, Achille. Necropolítica: biopoder, soberania, estado de exceção, política da morte. São Paulo: n-1 edições, 2018.

MONGA, Célestin. Fragmentos de um crepúsculo. Rio de Janeiro: Contraponto; São Paulo: Realejo, 2011.

MUDIMBE, V. Y. A Invenção da Africa. Gnose, Filosofia e a Ordem do Conhecimento. Portugal: Edições Pedago, 2013a. . A Ideia de África. Portugal: Edições Pedago, $2013 b$.

NASCIMENTO, Sergio Luis do; OLIVEIRA, Julvan Moreira de. A construção do legado: a negação de uma epistemologia filosófica africana. In Revista da ABPN, vol. 8, $\mathrm{n}^{\circ}$. 19. Março a Junho de 2016, pp. 177-194. Disponível em $<$ http://abpnrevista.org.br/revista/index.php/revistaabpn1/article/view/31/28>. Acesso em: 20 jan. 2020.

NORVAT, Manuel. Le Chant du Divers. Introduction à la philopoétique d'Édouard Glissant. Paris: L'Harmattan, 2015.

OLIVEIRA, Eduardo David. Filosofia da Ancestralidade: Corpo e Mito na Filosofia da Educação Brasileira. Curitiba: Editora gráfica Popular, 2007. 
OYĚWÙMÍ, Oyèrónkẹ. A invenção das mulheres: Construindo um sentido africano para os discursos ocidentais de gênero. Tradução para uso didático por Wanderson Flor do Nascimento e revisão de Aline Matos da Rocha. Título original: The invention of women: Making an African Sense of Western Gender Discourses Minneapolis: University of Minnesota Press, 1997.

QUIJANO, Anibal. Colonialidade do poder e classificação social. In SANTOS, Boaventura de Sousa; MENESES, Maria Paula (orgs.). Epistemologias do Sul. São Paulo: Cortez, 2010, pp. 84130 .

RAMOSE, Mogobe B. Sobre a Legitimidade e o Estudo da Filosofia Africana. Rio de Janeiro: Estudos Filosóficos- Revista de Filosofia, 2011.

SANTOS, Milton. A natureza do espaço: técnica e tempo - razão e emoção. São Paulo: Edusp, 2002.

SANTOS, Luís Carlos Ferreira dos. (2019) O poder de matar e a recusa em morrer: filopoética afrodiaspórica como arquipélago de libertação. 2019. 237 f. Tese (Doutorado em Difusão do Conhecimento) - Faculdade de Educação, Universidade Federal da Bahia, Salvador, 2019.

SARR, Felwine. Afrotopia. Brasil: n-1 edições, 2019.

SODRÉ, Muniz. A Verdade Seduzida: por um conceito de cultura no Brasil. Rio de Janeiro: Livraria Franciscvo Alves Editora S.A., 1988.

TOWA, Marcien. A ideia de uma Filosofia negro-africana. Belo Horizonte: Nandyala; Curitiba: NEAB-UFPR, 2015.

Recebido 30/11/2019

Aprovado em: $30 / 01 / 2020$ 